\title{
VERSITA
}

10.2478/cris-2013-0004

\section{SHADES OF PURPLE STRATEGY}

STEFANO CAVAGNETTO

BRUCE GAHIR

The aim of this paper is to first provide a methodological synthesis of the theories of Blue Ocean and Red Ocean Competitive strategies and then to offer a formal analysis of both strategies drawing upon on the work of Burke, Stel and Thurik (2009) and their investigation about the relationship between Blue Ocean and Red Ocean strategy considering different time horizons. Finally a discussion on the concept of a Purple strategy with a suitable formalisation is provided. 


\section{INTRODUCTION}

The field of business strategy uses the metaphors of Red and Blue Oceans to describe the types of strategies that are prevailing in the business arena.

Red Ocean represents all the current industrial concerns within a specific market. In this model, the industry's borders are set and accepted by all the players that know the rules of the game. The main purpose of firms in this business arena is to outperform the other firms in order to gain a greater share of the demand arising from consumers. The overall dynamic in this market conception is that, after a certain amount of time, the space available to firms in the market gets crowded with the consequence of lowering prospective profits and in the end possible growth. The resulting outcome is that products and services become commodities or niches, and cut throat competition turns the ocean, (the market), blood red.

In the strategic approach called Blue Ocean the focus is on all the industries not in existence today. This strategic model focuses on market places that are not currently known. The main characteristic of these markets is that they are untainted by competion and the leading idea is that firms create demand instead of competing for it. These elements make the model appealing because of the prospective rapid growth. The main claim behind this approach is that competition is irrelevant because players do not know the rules of the game that can be set over and over again as long as the market shift to untapped markets can happen. From this arises the adjective Blue Ocean to mean and address the analogy of a wider, deeper potential of the market space that is still unexplored and untainted.

In this strategic approach ' Value Innovation' takes a predominant role in the development of strategy, according to Kim and Mauborgne (2005a). A new market is originated when a firm realises value innovation which creates value at the same time for consumers and the firm itself. In this respect it is important to notice that innovation in this model is of a different type from innovation as conceived in Porter's analysis $(1998,2000)$. Blue Ocean innovation is innovation as described where imagination and vision are the leading factors of the business dynamic and development using the ideas of Von Mises (1949). The value created by innovation is reducing and eliminating simultaneously the value of products, services, and delivery which are valued less by the current or future market.

In Kim and Mauborgne (2005a), it is argued that while traditional Red Ocean strategies are necessary conditions for market development, at the same time they are not a sufficient condition for sustainable performance. Firms need to go beyond competing, to gain new profit and new potential growth oportunities which means that they also need to create Blue Oceans suggested by Kim and Mauborgne (2005a).

A classic approach from Red Ocean strategists to sustain themselves in the market place is to focus on creating advantage over the competition. This is mainly achieved by analysing and assessing what their competitors do and to aim at doing better. The typical mindset here is to conceive the market as finite, as a zero sum game where the goal is to get a bigger share. In this perspective, a firm's gains are obtained at the expense of others. The main reason for this structural approach to competition is because Red Ocean strategists focus most of their attention in dividing the finite market to search for new opportunities knowing that growth is increasingly limited. The outcome of this strategic approach is that industries are classified as attractive or unattractive ones, and this is the main decisive factor for strategic management in deciding whether to enter or not. 
On the other hand, Blue Ocean strategists think that market boundaries and finiteness exist only in the minds of managers and executives. They do not let existing market structures restrict their strategic reasoning. Thus, strategists following a Blue Ocean model, including Kim and Mauborgne (2005a), think that an extra demand is out there and largely intact. The real challenge is how to create it in order to reach untapped markets.

What the Blue Ocean is then suggesting is a shift from supply to demand, going from competition to the creation of innovative value. This will make accessible new markets and new demand. Blue Ocean strategy relativises the categorisation of ' attractive industry' per se because firms can alter the level of attractiveness with strategic moves and efforts that change the market structure.

The most important result of this operation is the fact that competition as interpreted in the old game becomes irrelevant (or at least it is not seen as a leading force). By unfolding the demand side of the economy, new opportunities and potentially new wealth is created. Organisations can as a result play a non-zero sum game in which at the end there are higher payoff possibilities. The change of the market structure offers a new perspective in which a firm's loss or gain of utility is not exactly balanced by the losses or gains of the utility of the other competing firms.

It is important to notice that both strategic approaches emphasise the fact that is important for firms to avoid high levels of competition, though a different role and weight is given to it. The reasons why intense competition must be avoided are, of course, different. In general, in the case of the Red Ocean model, avoiding intense competition has much to do with the conception of the firm and its resources. A firm in the Red Ocean Model is seen as fully resource based on Penrose (1959); this approach leads to a view in which uniqueness of resources limit the imitation processes, and at the same time creates a sustainable competitive advantage and increases profits, as detailed for example by Amit and Schoemaker (1993) and Peteraf (1993).

Given the fact that market opportunities are rapidly changing, the leading force is then the continuous development of unique resources and sustainable competitive advantages because otherwise the risk is that more firms will make their entry into the market playing the imitation game and then reducing profits and eroding the global growth of the sector. In literature, works such as Black and Boal (1994), Teece et al. (1997), and Winter (2003) tend to emphasise the relevance for organisations to develop their dynamic capabilities. If firms are able to continually create new resources which are unique this will facilitate new advantages, sustainable in the long term over competitors, opening new future profit opportunities. An important remark here is about the speed of the imitation game played by the firms. As discussed extensively in Porter $(1980,1985)$ the faster that process mimicry occurs, the greater the race to profit reduction. In Porter $(1980,1985)$ it is also argued that this dynamic is quick, and the imitation process is very rapid. Thus the main concern of strategic management becomes ' survival' by engaging in zero sum game competition between firms.

In this respect, the function of innovation is that of offering a short term solution; however in the longer term, the imitation game will force organisations to get involved in higher levels of competition, and it will make them focus on winning competitions.

There are interesting and remarkable differences between the two strategic approaches described so far. First of all, they are based on entirely different empirical conjectures: the pace at which profits are eroded by imitative behaviour is different, as addressed by Burke, Stel and Thurik (2009). 
One can observe that the Blue Ocean strategy has a more positive view of the possible effects of innovation on the profits of firms. With enough barriers to imitation and an unlimited availability of untapped markets that can be found by firms followed by constant innovation creating new demand for consumers, then the principle strategic concern of organisations is becoming to move from managing effectively competition to managing innovation. From a management point of view, the objectives of strategic management is actually to manage effectively innovation and not competition. Thus, in Kim and Mauborgne (2005a), Blue Ocean strategy is proposed as a universal choice for management. Using value innovation organisations will be able to find a suffient number of unexplored markets resulting in new consumer demand, while growing by avoiding conflict with competitors and getting involved in a cut throat game. From a philosophical point of view, this is a very important paradigm shift because it implies that the classic interpretation of competition and its meaning is undermined or at least weakened.

On the other hand, the Red Ocean school of thought emphasises that the assumption about the existence of untapped markets is a heavy assumption that they cannot be fully certain of. Even in the case of the existence of plenty of untapped markets, if it is discovered, it is only in the short term that this distracts from the fundamental and prime business activity which is competition among different firms.

To analyse and compare the two strategic approches means essentially to see which assumptions are more solid from the empirical evidence at our disposal, but also to assess in the short and long terms the consequences and implications of these assumptions.

The time horizons, short term and long term, perhaps are a way to assess the effectiveness of the models. Maybe Blue Ocean strategy does perform better in the short term while Red Ocean does better in the long term scenario, or maybe vice versa. Of course, if this would be the case, the evidence would suggest that value innovation generated by new organisations could create short term competitive advantage with resulting greater profitability but when the imitation game starts and competition gets more intense the effect on the long term, when the number of firms increases, would be a reduction of the average profits. An opposite scenario in which Red Ocean dominates in the short term and Blue Oceans dominates over the long term, resulting in a situation where innovation value drives the main strategies, would take longer to generate an increase of profits. In the short term the situation would be dominated by a tougher fight between competing firms over a given market waiting for the new markets to be opened.

The next section outlines the two strategic models in more detail building on the work of Burke, Stel and Thurik (2009). Following Burke, Stel and Thurik (2009) the set up of Beach Theory is used to compare Red Ocean and Blue Ocean strategic approaches.

\section{THE RELATIONSHIP BETWEEN THE NUMBER OF ORGANISATIONS AND AVERAGE PROFITS FOR BLUE OCEAN AND RED OCEAN COMPETITIVE STRATEGIES USING THE BEACH MODEL}

A common theoretical framework within which Red Ocean and Blue Ocean strategies can be compared is called Beach Theory identified by Hotelling (1929). Beach theory offers a suitable framework to analyse and discuss the fundamental assumptions of both strategic schools of thought.

The core of Beach Theory can be illustrated by the following situation: there are $\mathrm{n}$ ice cream vendors (firms); every vendor is denoted by $V_{n}$. Products and services are denoted by Pi and Sk, respectively. In the model it is assumed that $V 1(P 1, \ldots, P j, S 1, \ldots, S t)=V 2(P 1, \ldots, P j, S 1, \ldots, S t)=\ldots=V n(P 1, \ldots, P j, S 1, \ldots, S t)$. Let $L 1$ be the location of the vendor $\mathrm{V} 1$. Then it is postulated that $\mathrm{L} 1 \neq \mathrm{L} 2 \neq \ldots \neq \mathrm{Ln}$. The vendors are identical in 
products and services with the exception of the location. From the formalisation one can see that the only element differentiating vendors from the perspective of the consumer is the more convenient position. Ice cream is bought by a consumer using the criteria of the shortest distance. In other words, consumers buy ice cream from the vendor which is positioned the closest.

In Figure 1 one can see the best location/differentiation strategies of three vendors selling ice cream on a beach where it is assumed that the consumer density is equally distributed along the business space. The Red Ocean model is well illustrated by the competitive process depicted in Figure 1. In this context, the first step for all vendors is to maximise their profits using differentiation to win more consumers. In this scenario if a another vendor is added to the business space, then it will lead actual vendors to differentiate more themselves by relocating along the beach because location $L$ is the only relevant variable in the game. In this respect the entrance of the new vendor will contribute to geometrically redesign the ' business space' taking for granted that the distribution of customers will stay constant. Since the consumer variable is constant, then with an extra vendor competing in the same business space, each vendor will face an increasing struggle, resulting in lower profits. Therefore, following on from this, as masterfully shown by Porter (1980, 1985), more vendors (and in general, more firms) results in a greater competition, and in the end, lower profits.

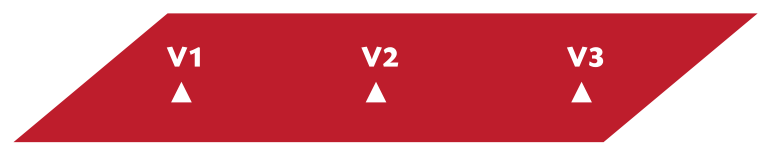

Figure 1: Three vendors V1, V2, and V3 and a single beach (business space)

In Figure 2 one can see the two strategic approaches on a common ground. Two new beaches are added to the model with new vendors; the new ' business spaces' are untapped markets in which potentially the zero sum game can be turned into a non-zero sum game.

In this case, in the new business spaces (new beaches) the demand for ice cream may not be evident to other vendors before a new vendor starts selling ice cream on them. Notice that the model implies that the part of sand may not even be considered an actual beach without the ice cream vendor sitting on it. In this respect, the market structure is modified by adding a new space available for new business possibilities. In Figure 2 one can see the result if one vendor relocates. By relocating from the actual beach to one of the new sand spaces available, and at the same time a new vendor is entering the other new beach, the resulting situation is that the total number of vendors has grown, and then the average profit has subsequently grown because the new vendors have found other unused markets which are not working under the condition of the zero sum game.

A valuable strategy in this perspective is that of conceiving innovation as going into or moving to a new business space to meet the demand with their offerings in these unused markets and after to differentiate themselves. In this respect this is still a form of differentiation. Now since the new business space is enlarged, the vendors will be located further away, so each vendor has potentially a bigger consumer base and greater profitability than previously, given the constant distribution of consumers. A necessary remark is that the reasoning behind this strategy works if the distribution of consumers is kept constant and in some sense the untapped markets have a uniform density of potential consumers which is of almost the same level as the previous existing markets. 


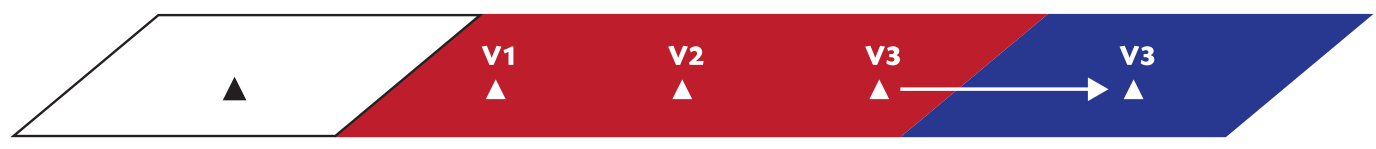

Figure 2: A mix of Red Ocean and Blue Ocean Strategies and three market spaces available

In the end, the outcomes illustrated in Figure 2 are coherent with both Red Ocean and Blue Ocean strategic models. By generalising the reasoning above, one can think of adding an unlimited number of untapped beaches (markets) to iterate the model on a larger scale.

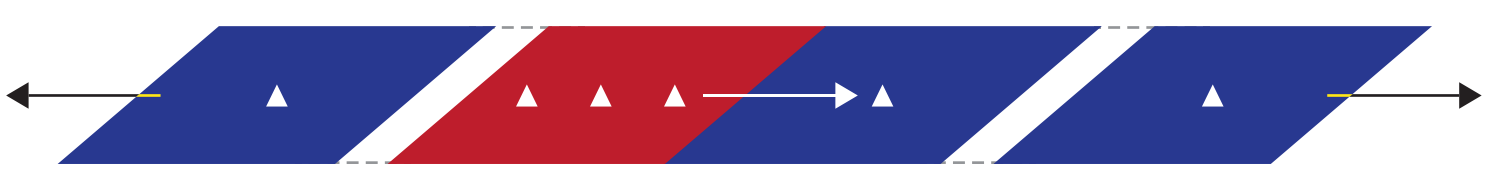

Figure 3: A mix of Red Ocean Competitive and Blue Ocean Strategies with the presence of untapped markets available

If the previous reasoning is sound by adding unlimited untapped markets, then it is possible to conclude that the strategic approach of Blue Ocean may potentially provide over the long run a positive relationship between average profits and number of organisations in the market. The main reason for this is that the strategy tends to shift a zero sum game into a non-zero sum game constantly. On the other hand, one may also see why Red Ocean strategy views this relationship negatively.

The key point is about the main assumption behind the Blue Ocean model: there exists a sufficiently large number of (potentially unlimited) untapped, unused markets where to discover new demands. Of course if the situation is the one illustrated in Figure 2, then in the long term, the average profits of vendors will fall as more vendors enter the business space and they compete for limited markets keeping the distribution of consumers constant (same density) and $\mathrm{L}$ as a unique relevant variable.

The scenario depicted in Figure 3 where the dashed lines and the external arrows display the existence of other (potentially unlimited) unused beaches with consumers who would like to buy ice cream, but at the moment they cannot have access to it. If new vendors enter these new and virgin markets by modifying the business space instead of going into known markets and having to compete with existing vendors, then the increase in vendors should result in increasing average profits given the enlargement of the overall business space.

Burke, Stel and Thurik (2009) propose four relevant claims:

\section{CLAIM 1}

"In the long term a negative relationship between average profits in an industry and the number of firms is consistent with the dominance of Competitive strategy [Red Ocean] over Blue Ocean strategy"(Burke, Stel and Thurik, 2009).

Notice that this of course works if one assumes that resources are limited and the business space is finite (market finite). In this case the claim works under the assumption that the existence of untapped markets is not a realistic option.

The second claim takes into account the positive correlation between average profits in an industry and the number of firms when a Blue Ocean strategy dominates a Red Ocean strategy. 


\section{CLAIM 2}

In the long term a positive relationship between average profits in an industry and the number of firms is consistent with the dominance of Blue Ocean over Competitive strategy [Red Ocean]"(Burke, Stel and Thurik, 2009).

This of course works if one assumes that resources are unlimited and the business space is infinite (market infinite or at least a sufficient number of untapped markets). In this case the model works under the assumption that unlimited untapped markets exist.

From the description above, it appears evident that the crucial difference between the two strategic schools of thought is the difference in the assumption that there exists (Blue Ocean) or not (Red Ocean) a number large enough of unused markets that can be reached employing value innovation to the extent that more organisations operating means essentially a reduction in competition. As a methodological remark this observation is relevant as it means that both strategies are not universal strategies per se, but they are market strategies under specific conditions closely related to the market structure. Following the example of the ice cream vendor business illustrated before in the case of the Beach Model, this can be translated into the following question: are there enough untapped and unused sandy coasts ready to be converted into beaches to create new business spaces and turning the business competition from a zero sum game into a non-zero sum game?

Burke, Stel and Thurik (2009) then consider the short term horizon. Giving the cost of value innovation (for example the reconstruction of facilities, the development of new products, and the brand development costs), it seems realistic to assume that in the short term a Blue Ocean strategy may cause a negative relationship between average profits and the number of firms present in the business space.

However as discussed in Burke, Stel and Thurik (2009), when a temporal variance is not considered and a Blue Ocean strategy is implemented, the rise in number of organisations that use Blue Ocean strategy may lead to either a growth of the average profits or not, depending on the success of organisations in the market.

In general, by accepting the conclusions of Burke, Stel and Thurik (2009), it is possible in terms of forecasting to see the relationship between profits and the number of organisations present in the market using a Blue Ocean strategy theory may be positive or negative where all outcomes are all equivalently possible. The same conclusions can be reached considering a Red Ocean strategy, and therefore it seems reasonable to consider short term horizons and the relationship between average profits and the number of organisations do not support any of the two schools of strategic management thought as discussed by Burke, Stel and Thurik (2009).

The third and the fourth claim deals with the speed of adjustment parameters. These are considered both in terms of number of firms and in terms of average profits by Burke, Stel and Thurik (2009). Adjustment parameters tell how fast the market reacts to unsustainable and too high profits by imitative entries. In this case, the claims put forward are:

\section{CLAIM 3}

"A rapid adjustment process of the number of firms and excesive profit level back to sustainable levels (high speed adjustment) is consistent with the dominance of a Competitive strategy [Red Ocean] strategy over a Blue Ocean strategy" (Burke, Stel and Thurik, 2009).

In the case of the opposite dominance, the claim shows a slow speed adjustment providing evidence that innovators have increasing opportunity to gain high profitability from their value innovation. 


\section{CLAIM 4}

"A slow adjustment process of the number of firms and excessive profit levels back (low speed of adjustment) is consistent with the dominance of Blue Ocean strategy over Competitive strategy [Red Ocean] strategy" (Burke, Stel and Thurik, 2009).

Claims 1 to 4 put forward by Burke, Stel and Turik (2009) have inherent assumptions that govern the dynamics of competition, including assumptions such as:

1. Limited resources and finite space for Red Ocean strategies;

2. Unlimited resources and infinite space for Blue Ocean strategies; and

3. Process of adjustment incorporating the "speed of adjustment paramater" of firms indicating when Blue Ocean strategy prevails over Red Ocean.

The degree to which Blue Ocean or Red Ocean strategies prevail in the market is related to the level of competition and the density of firms that are present in the arena. The degrees of different strategies and the speed of adjustment point to a process. If the process is fast this would imply that innovations are easy to replicate with a negative impact on profits as indicated by Claim 1.

Of course a slow process offers more time to value innovators to collect the fruits of the profits generated, and in this case, the competitive process acts like a weak mechanism in bringing profits back down. This process is therefore continually evolving between the Red Ocean and the Blue Ocean.

The main problem for this approach is that its assumptions seem a bit unrealistic on one side and a bit too optimistic on the other side. Developments in the last decades in the mobile phone industry seem to suggest a more fuzzy model where Red and Blue mix and a sort of Purple Ocean is more of a realistic explanation, or at least a more down-to-earth modelisation.

We now incorporate these assumptions and ideas of Blue Ocean and Red Ocean strategies as evolutionary processes to further develop the Beach Model presented in this section in order to develop a new model that in our view can better fit reality and the dynamics in business environments. What empirical evidence seems to suggest is that managers do not have to face a choice between either the first or the second strategic approach since the following theoretical analysis suggests that the two models overlap in several elements, and above all, the Blue Ocean does not completely remove competition, but it acts to postpone the competition by focusing on value innovation.

\section{DEVELOPMENT OF PURPLE OCEAN MODEL}

Products and services are denoted by $P_{i}$ and $S_{k}$ respectively and the vendor is denoted by $V_{n}$ such that:

$$
V_{l}\left(P_{l}, \ldots . . P_{j}, S_{l}, \ldots ., S_{k}\right) \text { is a vendor } V_{l}
$$

If we further consider vendors as elements of a set $R_{0 I}$, where $R_{0 I}=$ set of all vendors following Red Ocean strategies such as $x_{l}, \ldots . . x_{n}$ then we can denote $V_{I l}$, vendor 1 , following Red Ocean strategies of type 1 as an element of the set $R_{01}$ as follows:

$$
V_{I l}\left(P_{1 l}, \ldots \ldots P_{1 j}, S_{I l}, \ldots . . S_{l k}, x_{1 l}, \ldots . . x_{l n}\right)
$$


And another vendor $V_{21}$ in a similar way following Red Ocean strategies of type 2:

$$
V_{2 l}\left(P_{2 l}, \ldots \ldots P_{2 j}, S_{2 l}, \ldots . . S_{2 k}, x_{2 l}, \ldots \ldots x_{2 n}\right)
$$

And since we are assuming that $V_{11}=V_{12}$ this implies that:

$$
\begin{gathered}
P_{11}, \ldots \ldots P_{1 j}=P_{2 l}, \ldots \ldots P_{2 j} \\
S_{11}, \ldots . . S_{1 k}=S_{2 l}, \ldots . . S_{2 k} \text { and } \\
x_{11}, \ldots . . x_{1 n}=x_{21}, \ldots . . x_{2 n}
\end{gathered}
$$

where $x_{11}, \ldots . x_{1 n}$ and $x_{2 l}, \ldots . x_{2 n}$ can be considered as generic competitive strategies that generate competition in the Red Ocean domain.

Employing the theorems from set theory, we can therefore say that the above vendor equality assumption leads to the equality condition for the two red Ocean sets as follows:

$$
\left(R_{01}=R_{02}\right) \Leftrightarrow\left(\left(\forall V_{1 n} \in R_{01} \Rightarrow V_{1 n} \in R_{02}\right) \text { and }\left(\forall V_{2 n} \in R_{02} \Rightarrow V_{2 n} \in R_{01}\right)\right)
$$

This would also imply that $R_{01}$ and $R_{02}$ are not mutually exclusive as shown by Figure 4 .

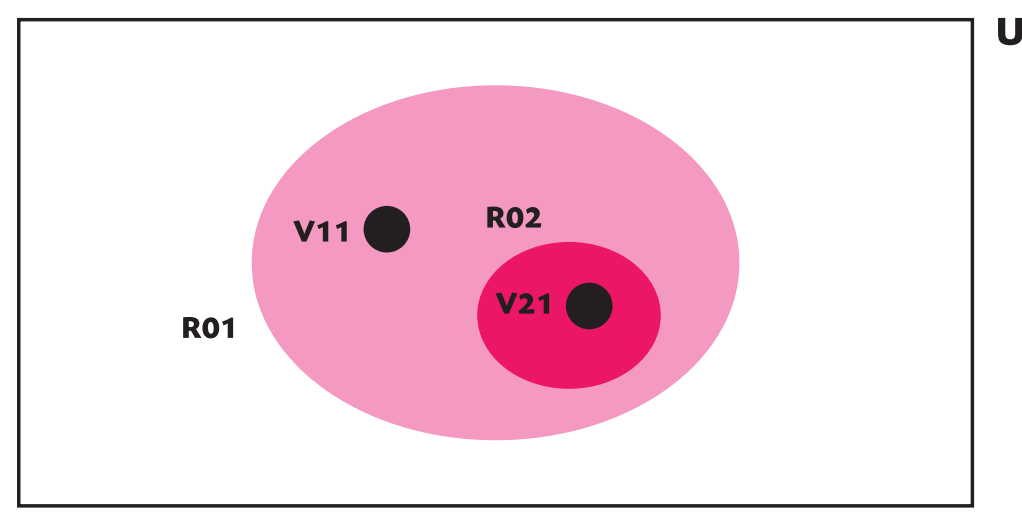

Figure 4: Two vendors following different Red Ocean strategies

We can therefore say that:

$$
R_{01} \subseteq R_{02}
$$

Defined by:

$$
R_{01} \subseteq R_{02} \Leftrightarrow \forall V_{2 n} \in R_{02} \Rightarrow V_{2 n} \in R_{01}
$$

Now consider vendors who follow Blue Ocean $(B O)$ strategies denoted by $y_{l}, \ldots . ., y_{n}$. For this example we consider two cases detailed below: 
CASE 1: VENDOR $V_{11}$ FROM THE $R_{01}$ OR $R_{02}$ SET MOVES TO THE BO SET $B_{01}$ AS SHOWN BY FIGURE 5

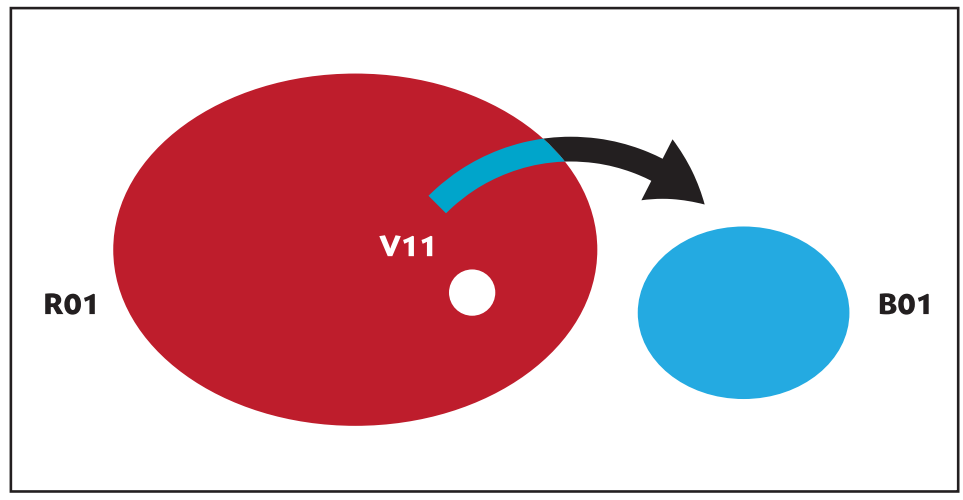

Figure 5: Vendor $V_{11}$ from the $R_{01}$ or $R_{02}$ set moves to the $B O$ set $B_{01}$

In this case we assume that the vendor has the same products and services as before; however the strategies are a mixture of value innovation and generic strategies for different product-service mixes.

If we let:

$V_{I I}\left(R_{0 I}\right)=$ Vendor 1 competing with Red Ocean strategies of type 1 in set $R_{01}$ and

$V_{1 I}\left(B_{0 I}\right)=$ Vendor 1 competing with Blue Ocean strategies of type 1 in set $B_{0 I}$

Then following from our earlier denotations, we could denote $V_{11}\left(B_{01}\right)$ as:

$$
V_{1 l}\left(B_{01}\right)\left(P_{1 l}, \ldots \ldots P_{1 j}, S_{11}, \ldots . . S_{1 k}, y_{11}, \ldots . . y_{1 n}\right)
$$

Further, if we now let $x_{11}, \ldots . x_{I n}$ be a set of Red Ocean strategies of type 1 for vendor 1 in set $R_{01}$ and $y_{11}, \ldots$. $y_{I n}$ be a set of Blue Ocean strategies for the same vendor in set $B_{01}$, then we could represent these strategies sets as follows:

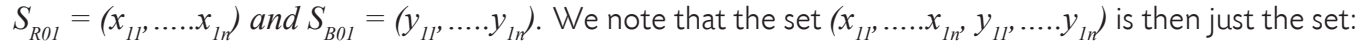

$S_{R 01} \cup S_{B 01}$ represented by Figure 6 .

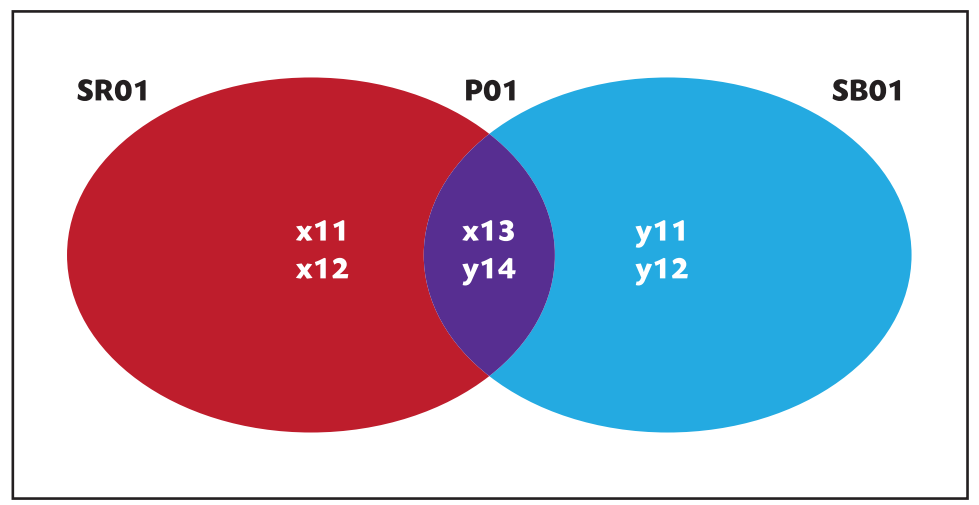

Figure 6: Sets of strategies for Blue Ocean and Red Ocean for one vendor 
The shaded region in Figure 3 indicates the region:

$$
S_{R 01} \cap S_{B 01}
$$

Indicating that the vendor $V_{I I}$ is competing in an arena that is a mixture of both Red Ocean AND Blue Ocean strategies, which we call the Purple Ocean arena adopting the Purple Ocean P01 strategy, where vendors are following a combination of strategies indicated by the above intersection.

\section{CASE 2: VENDOR $W_{11}$ FROM OUTSIDE THE BUSINESS ARENA ENTERS THE DOMAIN WITH BO STRATEGY AS INDICATED BY FIGURE 6}

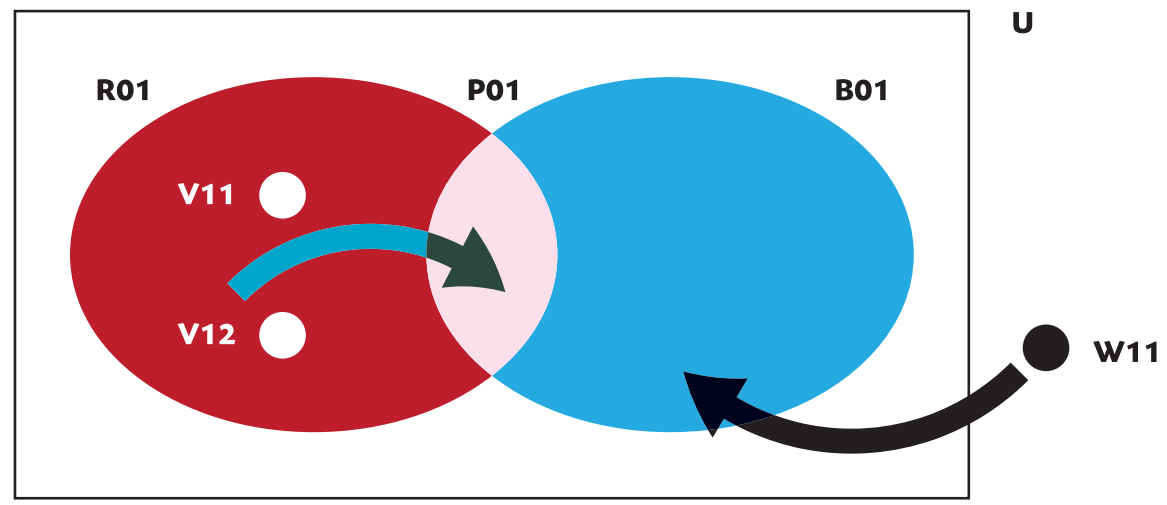

Figure 6: Illustrating Case 2 above

In this case, following our formulation earlier we could denote $W_{1 I}$ as:

$$
W_{l l}\left(B_{0 l}\right)\left(P_{l l}, \ldots \ldots P_{l j}, S_{l l}, \ldots . . S_{l k}, y_{l l}, \ldots . . y_{l n}\right)
$$

The situation here is different from case 1 as $W_{l l}$ will be a vendor entering the arena with $B O$ strategies and will therefore compete in the Blue Ocean region. As a greater number of vendors enter the Blue Ocean region, a movement of vendors will occur as illustrated by Cases 1 and 2 .

We can begin to see the evolution of different regions of Purple, which we call ' Shades of Purple'. The stages of evolution are shown below.

\section{Stage 1: Red Ocean strategies only - Competition}

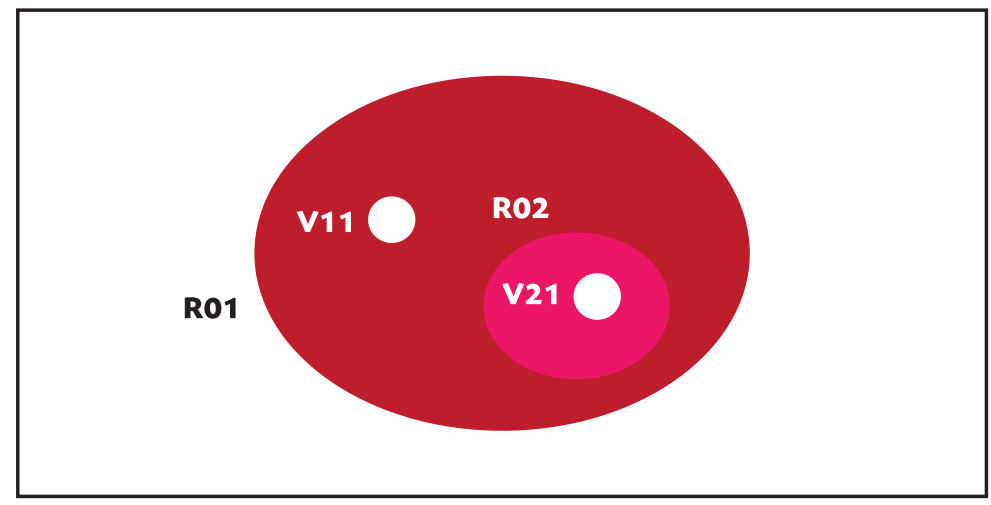


Stage 2: Blue Ocean strategies implemented to reduce competition, evolution of Purple Ocean strategies (arrow indicates the direction of evolution)

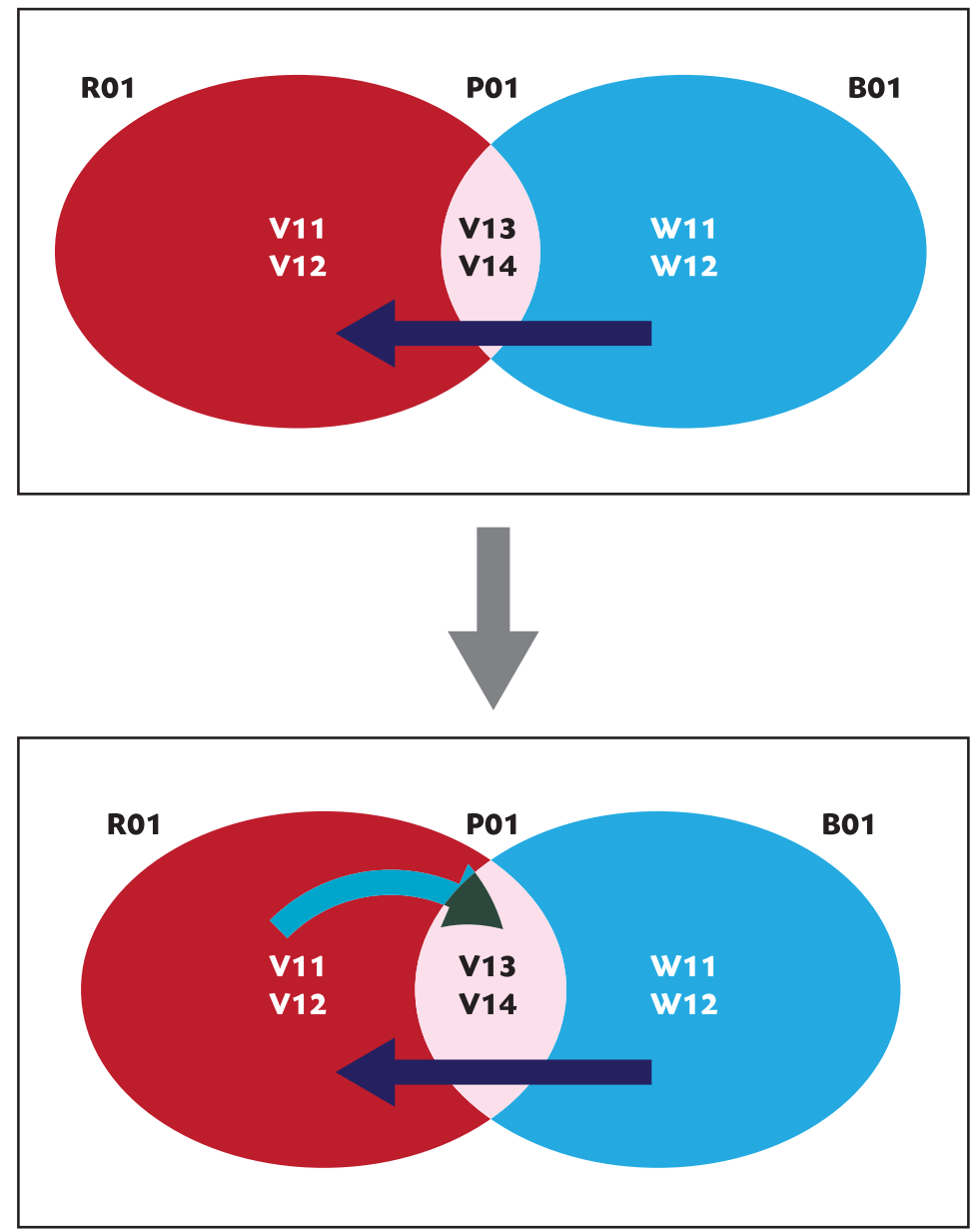

Stage 3: As greater number of vendors enter the Blue Ocean arena, the Purple Ocean arena increases

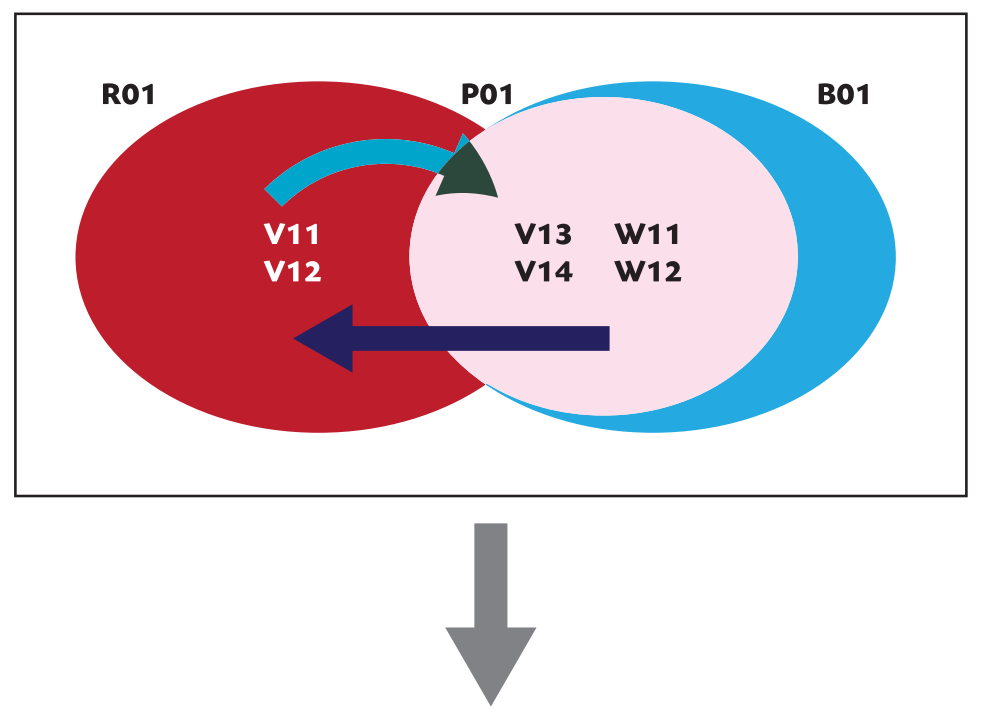




\section{Stage 4: Dominant Purple Ocean strategy evolving to Red Ocean}

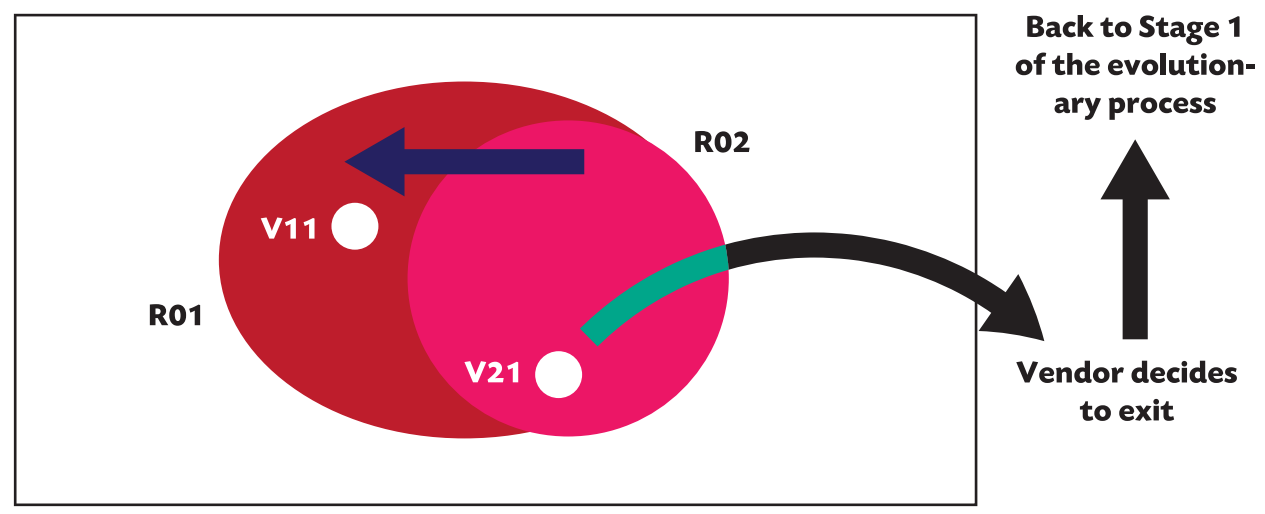

Stage 5: Final stage of the strategy evolution process, leads back to Stage 1

Following the above evolutionary process, one can note that there are no permanent Blue Oceans in reality. When competitors (vendors in our case) begin to imitate Blue Oceans they turn into Red Oceans. If markets become completely Red Oceans, vendors will choose to exit due to fierce competition and low profits. Therefore, in most cases, vendors are situated in the midst of Red and Blue Oceans - the Purple Oceans. Purple Ocean strategy advocates continuous innovation; numerous traditional enterprises such as Samsung, Nokia, and Motorola have done this and therefore avoided tumbling into the Dead Ocean.

Barwise and Meehan (2012) have detailed that Samsung can be cited as a classic example where Blue Ocean value innovation ( $\mathrm{VI}$ ) strategy has been utilised successfully in the Purple Ocean. Value innovation is defined as a systematic framework for developing new products that go beyond existing market parameters, precisely focusing on unused markets.

Firstly, by cataloguing the competitive industry factors, and secondly for exploring possibilities for the developments of innovative products to create competition free market space.

The statement that by using Blue Ocean strategy organisations can make the competition irrelevant seems to be an attractive fantasy. The main point behind this work is that any real-world strategy cannot make the competition irrelevant; in other words, there are no Blue Oceans, but rather Red and various shades or Purple Oceans. The Blue Ocean represents the moment of expansion to new untapped markets lead by value innovation, but when the market dynamic gets going, then the Red Ocean moves on with the forces of competition and imitation taking over the existing Blue Ocean and transforming it into a Purple Ocean, becoming increasingly Red.

The mobile phone market with competitors such as Motorola, and then Nokia and Samsung, are examples of the fact that Blue Oceans do not really exist. Nokia achieved market leadership at the expense of Motorola in the late 1990s and now Samsung has replicated the manoeuvre by doing the same to Nokia. Barwise and Meehan (2012) highlight that whilst Samsung put into practice Kim and Maubournge's Value Innovation framework in the 1990s, it was not able to create (nor was Nokia) an "uncontested market" space which could "make the competition irrelevant". Still in 1994 Motorola was the leader of the global mobile handset market with a 45\% share outperforming its closest competitor Nokia which was reaching around a 20\% market share. However, after about six years Nokia became the market leader with 31\% and continued to be the leader of the maket for almost all of the next ten years until the advent of Samsung's new strategy lead by the Galaxy generation of smartphones, as identified by Barwise and Meehan (2012). 
By analysing the strategies of both Motorola and Nokia, we can offer some explanations about the change in the leadership in the mobile market share and at the same time point to evidence that things in the market are often more complex than what the Red Ocean and Blue Ocean Models are telling us. To consider these strategies, we can use three strategic factors that contribute to build the Purple Ocean by mixing the Red and the Blue Ocean Models at different chromatic levels:

1. Progressive advancement: this is the product improvement that meets the demand in the Red Ocean, but is also working in possible untapped markets because it matches needs not existing yet, but that can be created on the basis of common human traits that are independent from culture to culture, from society to society, etc. In the Blue Ocean side it works as a brand promise, whereas in the Red Ocean it works as a highly competitive product because it differentiates enough from existing products. This progressive advancement leads to a relentless incremental product and process innovation that plays well where the market is crowded and it is a zero sum game and where the market can be described as a non-zero sum game.

2. Blue Ocean innovation: this is where the value innovation plays a crucial role and it is characterised by an aggressive switch on different territory and combined with a paradigm shift in the technology - tools already available in the Red Ocean but they are stuck because of the extremely high level of competition. This is not focusing on the next big thing coming out from research and development, but it is indeed a careful analysis, and research on the actual undeveloped resources already exist.

3. Adaptive organisational culture: this is the cultural element of the strategic model which is in relationship with the perception of the firm by its employees and at the same time the capability of the organisation to adapt and to consumers demand and feedback. This is highly affected by differences in cultures and society, and it requires divisions of small size that can provide faster reaction and response in targeting markets that are extremely diversified with respect to the dominate demand.

Thus, following Barwise and Meehan (2012) concerning point 1, the strategic approach of Motorola was focusing on being the first to introduce a new formidable product, while Nokia was mainly emphasising the constant improvement of the delivery of the promise through an incremental product innovation without losing the connection with the existing products. In point 2 above, the big move from Nokia was to go into unfamiliar markets for the firms and at the same time to change aggressively from analogic to digital mobile technology. At the same time Nokia's branding strategy was adapted, allowing a fast penetration of countries still under development. Finally, regarding point 3 above, Nokia took feedback from consumers seriously and restructured the whole organisation in 2003 to get closer to consumer demand and feedback in order to allow a faster response and to get better insight in the unexplored markets. The overall restructuring led to a very efficient and sophisticated consumer segmentation described by Gupta (2012).

Currently, as mentioned above, Samsung used the same strategic moves to overtake Nokia in market share; in this respect, Nokia is today where Motorola was in 1994. Thus, Samsung kept the basics in its strategy, unlike Motorola, but also has combined the classics "with a growing ability to innovate beyond the familiar" as Barwise and Meehan (2012) discuss. To avoid in the long run Nokia's situation, organisations need to create strategies dealing with the chromatic density of the Red component, whereby techniques such as Value Innovation may be extremely useful. The real goal is then for firms to create Purple areas of Ocean beyond the edge of actual markets with a constant organic evolution and reliable communication towards consumers regarding their core promise. Otherwise the risk is that they will end up quite quickly like Motorola. 
To conclude, one can say that it is very hard in reality see a truly and indubitably Blue Ocean. Even when it does exist, the company that creates it rarely achieves over the long run in market leadership. In real-world markets the dominant color seems to change over time from Red to Reddish-Purple to Purple, exhibiting different chromatic levels where Red is still a basic component.

\section{CONCLUSIONS}

The ideas presented in this paper have enabled the development of a tentative model that has been denoted as Purple Ocean strategy. An evolutionary process-based approach has been used incorporating the assumptions from the work of Burke, Stel and Thurik (2009). The choice of generic strategies is normally driven by the market, industry structure, characteristics of rivals and buyers, regulators, available resources, and other factors.

Each strategy is fundamentally a different approach to creating and sustaining competitive advantage, and we have noted that the common theme of all these generic strategies in how to compete in the same contested space; what we have denoted as the Red Ocean or the Blue Ocean. In our analysis of Blue Ocean strategies, we have emphasised that the focus is mainly on value innovation to influence the level of competition, and hence the degree of evolution from the Blue Ocean to the Red Ocean and vice versa.

A tentative model using a set theoretic approach has been suggested that incorporates the ideas presented in this paper and elaborates on the combination of these two strategies to develop the Purple Ocean strategy.

Following the evolutionary process developed in the model, one can note that there are no permanent Blue Oceans in reality. When competitors (vendors in our case) begin to imitate, Blue Oceans turn into Red Oceans. If markets become completely Red Oceans, vendors will choose to exit due to fierce competition and low profits. Therefore, in most cases, vendors are situated in the midst of Red and Blue Oceans, the Purple Oceans. Purple Ocean strategy advocates continuous innovation as evidenced by numerous traditional enterprises, but at the same time to focus on the right level of competition that cannot be excluded from the market model.

\section{ACKNOWLEDGEMENTS}

We would like to thank Gavin Bird, Marko Puskaric, and Dave Gannon. The former two for insightful comments about the technology industry and for useful comments on the final version of this paper. The latter for the on-going fruitful discussions about different business environments and for being an invaluable resource in drafting the different versions of this work. 


\section{REFERENCES}

Amit, R. and Schoemaker, PJH. (1993) "Strategic Assets and Organizational Rent", Strategic Management Journal, 14, pp. 33-46.

Barwise, P. and Meehan S., (2012) "Innovation beyond Blue Oceans", available at http://www.warc.com/Content/ ContentViewer.aspx?ID=18f256ca-3259-4487-a4b6-7453805e772berMasterContentRef=18f256ca-3259-4487a4b6-7453805e772berCampaign=WarcPrize2013erutm_campaign=WarcPrize2013 retrived June 15, 2013.

Black, JA, Boal, KB. (1994) Strategic Resources, Traits, Configurations and Paths to Sustainable Competitive Advantage, Strategic Management Journal, 15, pp. 131-148.

Brandeburger, A. And Harborne, S. (1996) "Value-based Business Strategy", Journal of Economics and Management, 5, 1, pp. 5-24.

Burke, A. Stel, A. and Thurik, R. (2009) "Blue Ocean versus Competitive Strategy: Theory and Evidence", ERIM report series research in management Erasmus Research Institute of Management, ERIM Report Series Research in Management

Hotelling, HH. (1929) 'Stability in Competition", The Economic Journal, 39, pp. 41-57.

Gupta, A. (2012) "NOKIA-Restructuring a Giant". Available at http://tejas.iimb.ac.in/articles/16.php. Retrived on June 20,2013

Kim, W. C. and Mauborgne, R. (2005a) Blue Ocean Strategy: How to Create Uncontested Market Space and Make Competition Irrelevant, Harvard Business Press, Boston.

Kim, W., Mauborgne, R. (2005b) "Blue Ocean Strategy: From Theory to Practice", California Management Review, 47, 105-121.

Kim, WCh, Mauborgne, R. (2005c). "Value Innovation: A Leap into the Blue Ocean", Journal of Business Strategy, 26, pp. 22-28.

Nokia - Story of Nokia, http://www.nokia.com/A4303001. Retrived on June 19, 2013.

Nokia - Structure, http://www.nokia.com/A4126325. Retrived on June 19, 2013.

Nokia - Research, http://www.nokia.com/A4946103. Retrived on June 19, 2013.

Penrose, E. (1959) The Theory of the Growth of the Firm, Basil Blackwell, London.

Peteraf, M. A. (1993) "The Cornerstones of Competitive Advantage: A Resource-based View", Strategic Management Journal, 14, pp. 179-191.

Porter, M.E. (1980) Competitive Strategy, Free Press, New York.

Porter, M.E. (1985) Competitive Advantage, Free Press, New York.

Porter, M.E. (ed.) (1986) Competition in Global Industries, Harvard Business School Press, Boston.

Porter, M.E. (1996) "What is Strategy", Harvard Business Review, November, pp. 61 - 78.

Porter, M.E. (1998) On Competition, Harvard Business School Press, Boston.

Porter, ME. (1998) "Clusters and the New Economics of Competition", Harvard Business Review, 76, pp. 77-90.

Porter, ME. (2000) "Location, Competition and Economic Development: Local Clusters in a Global Economy”,

Economic Development Quarterly, 14, pp. 15-34.

Porter, M.E. (2008) "The Five Competitive Forces That Shape Strategy", Harvard Business Review, January, pp. 79-93.

Ryal M., (2013) "The New Dynamics of Competition", Harvard Business Review, June, pp. 80-87.

Schumpeter, JA. (1934) The Theory of Economic Development, Cambridge, Harvard University Press.

Teece D.J., Pisano, G., Shuen, A. (1997) “Dynamic Capabilities and Strategic Management”, Strategic Management Journal, 18, pp. 509-533.

Von Mises, L. (1949) Human Action: A Treatise on Economics, London: Hodge.

Winter, S.G. (2003) “Understanding Dynamic Capabilities", Strategic Management Journal, 24, pp. 991-995. 